\title{
Spectroscopic studies of swift heavy ion irradiated nanophase mullite
}

\author{
H. Nagabhushana ${ }^{\text {a }}$, B.N. Lakshminarasappa ${ }^{\text {a,* }}$, S.C. Prashantha ${ }^{\text {a }}$, \\ K.R. Nagabhushana ${ }^{\mathrm{a}}$, Fouran Singh ${ }^{\mathrm{b}}$ \\ a Department of Physics, Bangalore University, Jnana Bharathi Campus, Bangalore 560 056, India \\ ${ }^{\mathrm{b}}$ Nuclear Science Centre, Aruna Asaf Ali Marg, New Delhi 110 067, India
}

Available online 24 January 2006

\begin{abstract}
Photoluminescence (PL) studies of $100 \mathrm{MeV}$ swift $\mathrm{Ag}^{8+}$ ion bombarded combustion synthesized nanophase mullite has been studied at room temperature (RT) and the results are reported here. A pair of PL bands, one broad band centres at $\sim 550 \mathrm{~nm}$ and another sharp one at $\sim 690 \mathrm{~nm}$ are observed with excitation by a $442 \mathrm{~nm}$ laser beam. However, when the sample is excited with $326 \mathrm{~nm}$ laser beam, three bands with peaks at $\sim 460,550$ and a well resolved one with peak at $760 \mathrm{~nm}$ are observed. It is observed that the PL intensity increases up to $5 \times 10^{11}$ ions $/ \mathrm{cm}^{2}$ and thereafter it decreases with increase of ion fluence. The pristine as well as $\mathrm{Ag}^{8+}$ ion irradiated mullites are characterized by infrared spectroscopy (IR) and X-ray diffraction (XRD) techniques. The decrease in PL intensity is attributed to Al-O and $\mathrm{Si}-\mathrm{O}$ bonds present as the surface getting amorphized. The effects of $\mathrm{Ag}^{8+}$ irradiation are compared to those obtained with $\mathrm{Ni}^{8+}$ ions and the results are discussed.
\end{abstract}

(C) 2005 Elsevier B.V. All rights reserved.

PACS: $07.65 . \mathrm{G} ; 32.50 . \mathrm{F} ; 41.80 . \mathrm{G} ; 81.20$

Keywords: Infrared spectroscopy; Photoluminescence; Ion beam; Amorphization

\section{Introduction}

Radiation effects in inorganic insulators have been a subject of rapidly growing interest in the past few years. A large field of potential applications exists for these materials and the development of various new techniques is directly related to the progress in this field. Swift heavy ions (SHI) are very useful for modifying the properties of films, foils and surface of bulk solids. Ions penetrate deep into the material and produce a long and narrow disordered zone along their trajectory.

In the present paper, we report the PL, IR and XRD analysis of $100 \mathrm{MeV} \mathrm{Ag}^{8+}$ irradiation effects in combustion synthesized mullite bombarded, for fluences in the range $1 \times 10^{11}-5 \times 10^{13}$ ions $/ \mathrm{cm}^{2}$. Mullite is an aluminum silicate

\footnotetext{
* Corresponding author. Tel.: +91 $809448116281 / 57659674$; fax: +9180 22961486

E-mail address: bnlnarasappa@rediffmail.com (B.N. Lakshminarasappa).
}

$\left(3 \mathrm{Al}_{2} \mathrm{O}_{3} \cdot 2 \mathrm{SiO}_{2}\right)$ crystallizes in orthorhombic. This is a promising, material for high temperature applications because of its low thermal conductivity. The silicate group of this mineral used in the production of non-fusion cast tank blocks in the manufacture of spark plugs and as a mineral specimens [1].

\section{Experimental}

Nanocrystallized mullite particles were synthesized by combustion technique using aluminum nitrate and diformyl hydrazine dissolved in a minimum quantity of double distilled water in a cylindrical Pyrex dish of $\approx 300 \mathrm{ml}$ capacity. To this, a silica fumes was added and dispersed well using a magnetic stirrer. The dish containing the heterogeneous mixture was introduced into a muffle furnace maintained at $500 \pm 10^{\circ} \mathrm{C}$. Initially, the solution boils and undergoes dehydration followed by decomposition with evaporation of large amount of gasses. The mixture then froze and swells, forming a foam which ruptures with 
a flame and glows to incandescent with a flame temperature of $1200{ }^{\circ} \mathrm{C}$. The final product is voluminous and weekly crystalline. The whole process lasts less than $5 \mathrm{~min}$. The crystallinity and particle size of final product was confirmed by XRD and scanning electron microscope [2]. The particle size is observed to be in the range of $100 \mathrm{~nm}$. Pellets of $1 \mathrm{~mm}$ thickness and $6 \mathrm{~mm}$ diameter were prepared using pestle and mortar and poly vinyl alcohol as binder and by applying a pressure of 6 ton per ram of $6 \mathrm{~mm}$ diameter using an home made pelletizer.

One sample was reserved as pristine for comparison with the irradiated ones. The irradiation was carried out on two identical samples. The mullite pellets were mounted on a vacuum shielded vertical sliding ladder having four rectangular faces. The samples are irradiated in Material Science chamber of the Pelletron accelerator at NSC under high vacuum $\left(6 \times 10^{-6}\right.$ Torr $)$ with $100 \mathrm{MeV} \mathrm{Ag}^{8+}$ ions with appropriate beam current of $\sim 2$ pna.

Photoluminescence measurements of $\mathrm{Ag}^{+}$ion irradiated mullites were carried out using an excitation source - Kimmon $\mathrm{He}-\mathrm{Cd}$ laser (442 or $326 \mathrm{~nm}$ ) with a power of 32 or $120 \mathrm{~mW}$. CCD detector was used to record PL spectra in the $400-1200 \mathrm{~nm}$ range. Infrared spectra of pristine and ion bombarded samples were recorded in the range 500 $4000 \mathrm{~cm}^{-1}$ using Pye Unicam SP3-300 spectrophotometer using nuzol solvent. The XRD study was carried out using a Rich-Siefert, XRD-3000-TT setup with ' $\mathrm{Cu}$ ' K $\alpha$ radiation.

\section{Results and discussion}

Photoluminescence of combustion-mullite bombarded with $100 \mathrm{MeV}$ swift $\mathrm{Ag}^{8+}$ ions at fluence in the range $1 \times 10^{11}-5 \times 10^{13}$ ions $/ \mathrm{cm}^{2}$ under excitation by 442 and $326 \mathrm{~nm}$ laser were recorded and the obtained results are presented in Figs. 1 and 2, respectively. Two PL bands, one centred at $\sim 550 \mathrm{~nm}$ and a sharp peak at $\sim 690 \mathrm{~nm}$ are observed with excitation at $442 \mathrm{~nm}$. However, when the sample is excited with $326 \mathrm{~nm}$ laser beam, two additional PL bands centred at $\sim 460$ and $760 \mathrm{~nm}$ along with

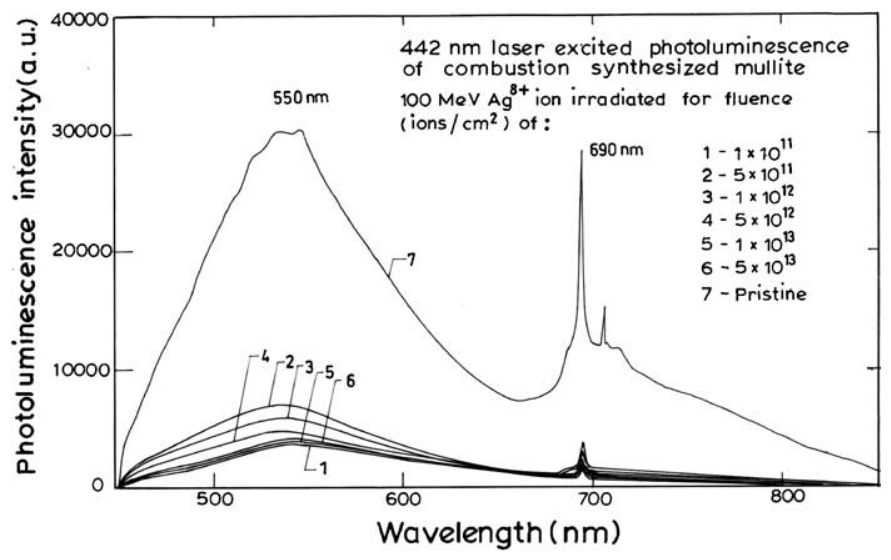

Fig. 1. Photoluminescence spectra $\left(\lambda_{\text {excitation }} 442 \mathrm{~nm}\right)$ of $100 \mathrm{MeV} \mathrm{Ag}^{8+}$ ion irradiated combustion synthesized mullite.

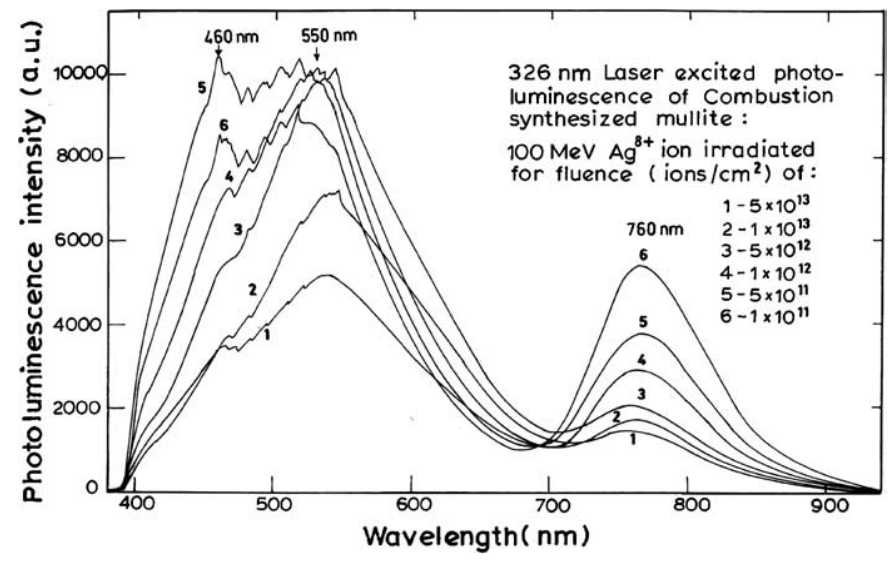

Fig. 2. Photoluminescence spectra $\left(\lambda_{\text {excitation }} 326 \mathrm{~nm}\right)$ of $100 \mathrm{MeV} \mathrm{Ag}^{8+}$ ion irradiated combustion synthesized mullite.

a broad and intense PL peak at $550 \mathrm{~nm}$ are observed. The $690 \mathrm{~nm}$ band is absent in the later case. It is observed that the intensity of these peaks increases up to a fluence of $5 \times 10^{11}$ ions $/ \mathrm{cm}^{2}$ and thereafter decreases with increase of $\mathrm{Ag}^{8+}$ ion fluence as can be seen from Figs. 1 and 2. The variation of PL intensity due to 442 and $326 \mathrm{~nm}$ excitation for various $\mathrm{Ag}^{8+}$ ion irradiated mullite are shown in Figs. 3 and 4 , respectively. The increase in PL intensity up to $5 \times 10^{11}$ ions $/ \mathrm{cm}^{2}$ is attributed to creation of additional defect centers responsible for PL during the bombardment process [3]. The decrease in PL intensity with further increase of ion fluence $\left(>1 \times 10^{11}\right.$ ions $\left./ \mathrm{cm}^{2}\right)$ implies some changes in the energy levels of the crystal resulting from the perturbation of the luminescent sites and from transient defect states formed during the bombardment process [4]. At fluence larger than $5 \times 10^{11} \mathrm{ions} / \mathrm{cm}^{2}$, the PL intensity becomes dose independent as a result of more damage occurred already in the sample. The sample in this case is supposed to be amorphized as a result of cascade quenching with swift heavy ion irradiation [5-7]. The susceptibility of amorphization may be measured with irradiation either at fixed temperature or at critical temperature. However, in

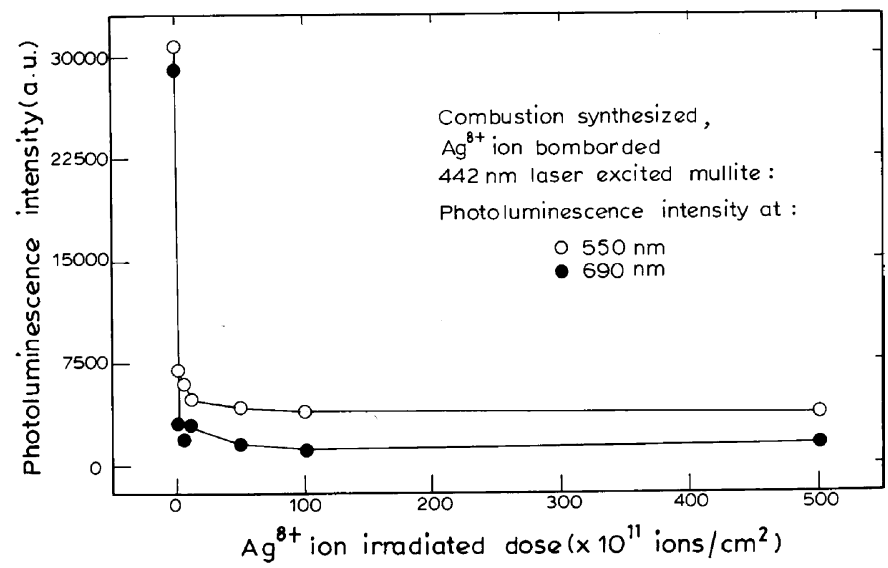

Fig. 3. Variation of PL intensity due to $442 \mathrm{~nm}$ laser beam excitation as a function of $\mathrm{Ag}^{8+}$ ion fluence in combustion synthesized mullite. 


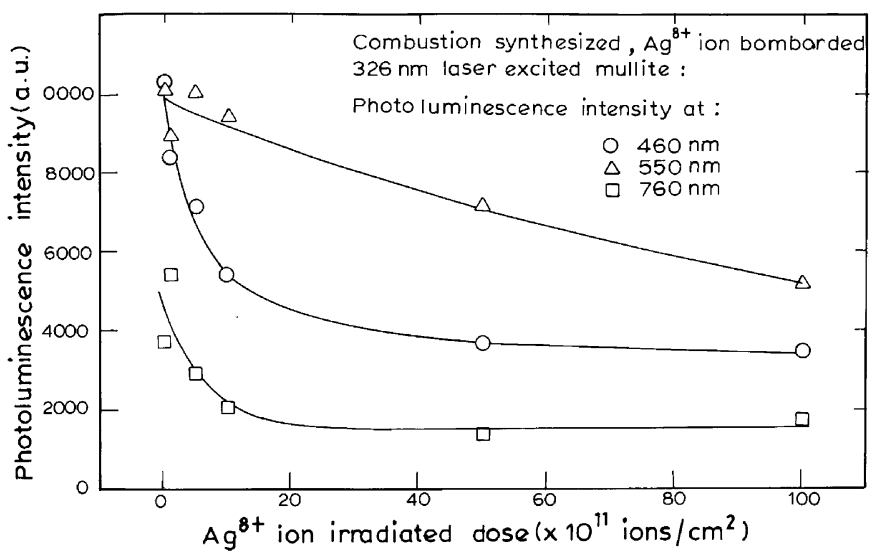

Fig. 4. Variation of PL intensity due to $326 \mathrm{~nm}$ laser beam excitation as a function of $\mathrm{Ag}^{8+}$ ion fluence in combustion synthesized mullite.

Table 1

Infrared absorption data of pristine and $\mathrm{Ag}^{8+}$ ion irradiated combustion synthesized mullite

\begin{tabular}{lll}
\hline Absorption $\left(\mathrm{cm}^{-1}\right)$ & Pristine sample & Irradiated sample \\
\hline $467-472$ & $\mathrm{Si}-\mathrm{O}\left(v_{4}\right)$ & $\mathrm{Si}-\mathrm{O}\left(v_{4}\right)$ \\
$566-571$ & $\mathrm{Si}-\mathrm{O}-\mathrm{Al}$ & $\mathrm{Si}-\mathrm{O}-\mathrm{Al}$ \\
$747-829$ & $\mathrm{Al}-\mathrm{O}$ & - \\
$2376-2929$ & $\mathrm{Si}-\mathrm{O}\left(2 v_{3}\right)$ & $\mathrm{Si}-\mathrm{O}\left(2 v_{3}\right)$ \\
$3441-3461$ & $-\mathrm{OH}\left(v_{1}, v_{3}\right)$ & $-\mathrm{OH}\left(v_{1}, v_{3}\right)$ \\
\hline
\end{tabular}

the case of swift $100 \mathrm{MeV} \mathrm{Ni}^{8+}$ ion bombarded mullite in the dose range $1 \times 10^{11}-5 \times 10^{13}$ ions $/ \mathrm{cm}^{2}$ with excitation by $442 \mathrm{~nm}$ laser beam, a broad emission band with peak at $\sim 557 \mathrm{~nm}$ besides a sharp emission band with peak at $\sim 705 \mathrm{~nm}$ was observed. The PL peaks in $\mathrm{Ag}^{8+}$ ion bombarded mullite are found to be shifted towards lower wavelength side with respect to those in $\mathrm{Ni}^{8+}$ ion irradiated samples [8].

The surface amorphization is confirmed by XRD measurements. They show that the material is crystalline up to $5 \times 10^{11}$ ions $/ \mathrm{cm}^{2}$ and thereafter, the decrease in peak intensity indicates the amorphization of the sample. Atomic force microscopy may throw some light on the formation of amorphization.

Infrared absorption spectra of pristine and $\mathrm{Ag}^{8+}$ ion irradiated mullite with fluences of $1 \times 10^{11}-5 \times 10^{13}$ ions/ $\mathrm{cm}^{2}$ have been recorded and the obtained data are given in Table 1. They clearly indicate to the characteristic absorption bands of silicates and water before irradiation of the samples [8]. It is further observed that the sharpness of the peaks increases in ion irradiated samples. This may be attributed to close packing units of tetrahedral $\mathrm{SiO}_{4}$ and/or octahedral $\mathrm{AlO}_{6}$ [8]. The decrease in PL intensity at $741-827 \mathrm{~nm}$ and $460 \mathrm{~nm}$ might be due to destruction of Al-O bonds [9] and, the destruction of these bonds with irradiation may further increase the amorphous nature of the sample. The irradiation is supposed to lead to reducing of packing units because of the energy deposited through electronic loss of swift heavy ions and of the formation of ion induced defects leading to non radiative recombination centers. These two processes are simultaneous consequences of irradiation and they compete with each other. Consequently, the enhancement or degradation of PL might be due to the balance between these effects [9].

\section{Conclusions}

PL of $\mathrm{Ag}^{8+}$ swift ion bombarded combustion synthesized mullite give rise to 550 and $690 \mathrm{~nm}$ bands and also 460,550 and $760 \mathrm{~nm}$ bands when the sample is excited by 442 and $326 \mathrm{~nm}$ laser light, respectively. The increase in $\mathrm{PL}$ intensity up to $5 \times 10^{11}$ ions $/ \mathrm{cm}^{2}$ is attributed to creation of new traps with bombardment process. The decrease in PL, XRD and IR intensity with increase of ion fluence is attributed to the amorphization of the material due to destruction of $\mathrm{Al}-\mathrm{O}$ bonds.

\section{Acknowledgements}

The authors wish to express their sincere thanks to Dr. D.K. Avasthi, Nuclear Science Center (NSC), New Delhi, for many useful discussions. Also, the technical staff of the NSC is gratefully acknowledged for their help and support.

\section{References}

[1] E.S. Dana, E.M. Ford, Minerology, Asia Publishing House, Bombay, 1962 , p. 617.

[2] H. Nagabhushana, Ph.D. thesis. Bangalore University, 2002, p. 62.

[3] H.M. Abdel-Hamid, H.M. Saad, S.M. Morsy, M.A. Hussein, Nucl. Instr. and Meth. B 129 (1997) 73.

[4] H. Nagabhushana, B.N. Lakshminarasappa, Fouran Singh, D.K. Avasthi, Rad. Measur. 36 (2003) 643.

[5] S.X. Wang, L.M. Wang, R.C. Ewing, Nucl. Instr. and Meth. B 127/ 128 (1997) 186.

[6] H.M. Naguib, R. Kelly, Radiat. Eff. 25 (1975) 1.

[7] T. Diaz de la Rubia, G.H. Gilmer, Phys. Rev. Lett. 74 (1995) 2507.

[8] H. Nagabhushana, B.N. Lakshminarasappa, Fouran Singh, D.K. Avasthi, Nucl. Instr. and Meth. B 211 (2003) 545.

[9] T.M. Bhave, S.S. Hullavarad, S.V. Bhoraskar, S.G. Hegde, D. Kanjilal, Nucl. Instr. and Meth. B 156 (1999) 121 